\title{
BOWEN'S DISEASE- A CASE REPORT OF A RARE CARCINOMA IN SITU
}

\author{
Manan Mehta1 ${ }^{1}$ Anuradha Priyadarshini², Gayatri Rajesh ${ }^{3}$, R. Sudha ${ }^{4}$, V. Mahalakshmi ${ }^{5}$
}

${ }_{1}^{1}$ Postgraduate Resident, Department of Dermatology, Sri Ramachandra Medical College and Research Institute. ${ }^{2}$ Assistant Professor, Department of Dermatology, Sri Ramachandra Medical College and Research Institute. ${ }^{3}$ Assistant Physician, Department of Dermatology, Sri Ramachandra Medical College and Research Institute. ${ }^{4}$ Professor, Department of Dermatology, Sri Ramachandra Medical College and Research Institute. 5 Professor and HOD, Department of Dermatology, Sri Ramachandra Medical College and Research Institute.

HOW TO CITE THIS ARTICLE: Mehta M, Priyadarshini A, Rajesh G, et al. Bowen's disease- A case report of a rare carcinoma in situ. DOI: 1. J. Evolution Med. Dent. Sci. 2017;6(83):5822-5824, DOI: 10.14260/jemds/2017/1264

\section{PRESENTATION OF CASE}

A 66-year-old female patient came with a chief complaint of skin lesion over the right arm since 5 years. The lesion initially started as a purple-coloured papule which gradually increased in size to form an erythematous scaly plaque. It was associated with occasional itching and minimal discharge on scratching. The lesion showed no resolution with topical steroid, creams, antibiotics and emollients. There was no history of prior trauma to the site. She was a homemaker and there was no history of contact with pesticides, arsenic or radiation exposure. There was no history suggestive of immunosuppression.

No history of similar complaints in the past. There was no history of loss of weight or appetite. The patient was a known hypertensive for 3 years and was on oral medications for the same.

On examination, a single $6 \times 6 \mathrm{~cm}$ raised erythematous scaly plaque with areas of violaceous hyperpigmentation, irregular borders and surface crusting was present over the anterolateral aspect of the right arm. The base of the lesion was not indurated. (Figure 1). Regional lymph nodes were not enlarged. Systemic examination was normal.

Incisional biopsy was done which showed skin with focal hyperkeratosis and crusting on the epidermal surface, keratinocytes of the Malpighian layer showed nucleomegaly and loss of polarity. Occasional bizarre nuclei were seen. The underlying dermis showed dense inflammatory infiltrate composed of lymphocytes, plasma cells and melanophages. There was no evidence of dermal invasion. The histological features were suggestive of Bowen's disease. (Figure 2). The patient was initiated on treatment with topical 5- fluorouracil cream twice daily.

\section{DIFFERENTIAL DIAGNOSES}

Actinic keratosis, Basal cell carcinoma, Psoriasis, Squamous cell carcinoma and superficial spreading melanoma were considered.

\section{CLINICAL DIAGNOSIS}

Bowen's disease.

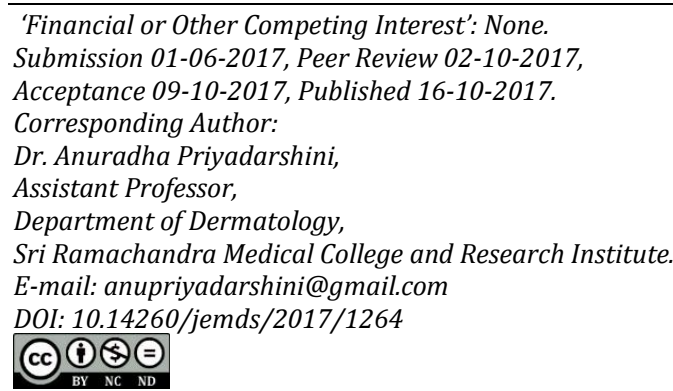

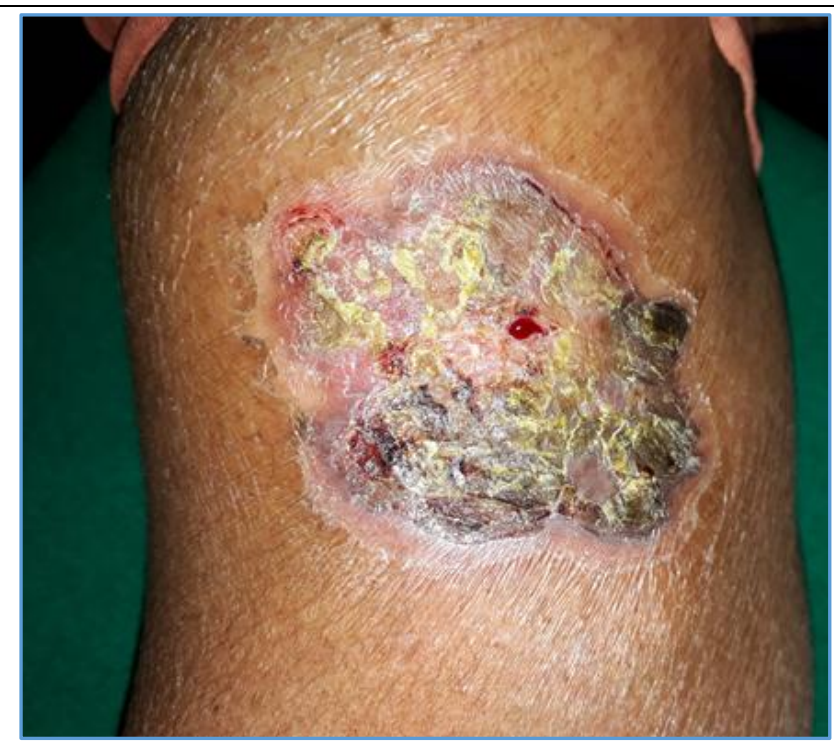

Figure 1. Single Erythematous Scaly Crusted Plaque with Areas of Hyperpigmentation on Right Arm.
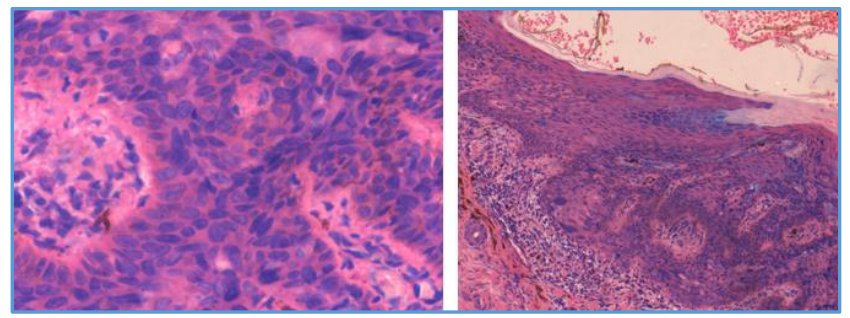

Figure 2. HPE of Skin Section showing Disarray of Keratinocytes with Atypical Hyperchromatic Nuclei, Loss of Polarity of Cells in the Malpighian Layer.

\section{DISCUSSION OF PATHOLOGY}

Bowen's disease (BD) is a pre-invasive squamous cell carcinoma in situ. It was first described by JT Bowen in 1912 as a precancerous dermatosis.(1) The eventual risk of progression to invasive squamous cell carcinoma and metastatic disease in a Bowen's is $3 \%$ to $5 \%$ for cutaneous Bowen's while it is up to $10 \%$ for genital Bowen's disease.(2)

The aetiological factors contributing to development of Bowen's Disease include solar and UV radiation, arsenic exposure, radiotherapy, immunosuppression, HPV and other Polyomavirus infection. Association with autoimmune diseases such as Sjogren's syndrome has been noted; however, no causation has been proven.(3)

Bowen's Disease is most commonly seen in elderly individuals and on sun-exposed sites such as head and neck and the upper limbs.(3) The appearance of Bowen's Disease on the extensor aspect of the arm in our patient, who is above 60 years of age is in keeping with most literature for solar/UV 
radiation induced pre-invasive NMSC. A study describing the distribution of Bowen's Disease with respect to age, sex and site noted that Bowen's Disease in lower limbs and of the cheek was most often seen in women than in men. ${ }^{(4)}$ Bowen's Disease can occur on any keratinised skin and has been reported from trunk and genitalia. The other less frequent sites of involvement are lip, nipple, palm, feet and nail bed.(5) Lesions on the trunk should raise the suspicion of chronic arsenic exposure.

The usual clinical presentation of Bowen's Disease is a single erythematous scaly or crusted plaque, which enlarges slowly over time. The scales are easily detachable, margins are well defined and it may be slightly raised.(3) Our patient presented with the classical clinical features of a gradually increasing scaly plaque. Other morphological patterns reported in literature are verrucous plaque, pigmented Bowen's disease (PBD). Pigmented Bowen's Disease constitutes $2 \%$ of $\mathrm{BD}$ cases, is more common in genital and interdigital sites, however, other sites such as digits, lip, umbilicus have all been reported. Clinically, Pigmented Bowen's Disease can mimic melanoma in situ.(6)

Bowen's Disease usually presents as a single lesion; however, cases of multicentric Bowen's have been seen. The probable aetiology of arsenic exposure or immunosuppression should be considered in such cases. (7)

Dermoscopy of Bowen's Disease shows 2 predominant features namely vascular patterns and scaly surface. The vascular pattern may be glomerular vessels or dotted. Pigmentary features of small brown or black globules, streaks and structure less (homogenous) pigmentation may be seen in PBD. $(8,9)$

Histopathology of Bowen's Disease shows complete disarray of keratinocytes in the epidermis, with crowded atypical keratinocytes, large, multilobulated, hyperchromatic nuclei, and atypical mitoses, giving a windblown appearance. The basement membrane is intact with no dermal invasion. The vessels in the papillary dermis may be dilated and associated with inflammatory infiltrate.(10,11) PBD shows the presence of increased melanin in basal layer and melanophages in the dermis. Many variants have been described in literature, such as psoriasiform, atrophic, papillated, clear cell, pagetoid and mucinous or sebaceous.(3) The possibility of Bowen's Disease being a marker for internal malignancy has also been considered. There are reports of association with lung and liver carcinoma. However, studies have not substantiated the association. The association of internal malignancy in a case of BD is higher when it is due to arsenic exposure or immunosuppression.(12)

\section{DISCUSSION OF MANAGEMENT}

The prognosis for Bowen's Disease in general is excellent since it is a slow growing lesion and responds well to treatment. There are many treatment modalities available including surgical excision, Mohs surgery, curettage, cryotherapy, photodynamic therapy, topical 5-fluorouracil and topical imiquimod.(13) There are rare case reports of selfresolving Bowen's Disease.(14)

Surgical modality has been the most commonly used modality in both UK and Australia.(15) It is recommended for size and sites where it is convenient and has the benefit of being a rapid, easy and cost effective method. For lesions on face, genital and digital lesions, Mohs surgery can be considered if feasible.(16)

Curettage with cautery, less often used, is another simple economical modality of treatment. The success of it; however, depends on the skill of the performing physician. The response is comparable to cryotherapy with the benefit of less pain and lower recurrence rates. $(14,15)$

Cryotherapy with liquid nitrogen is a simple method of treatment with the advantage of accessibility in outpatient setting. The clearance rates to cryotherapy varies considerably. It is said to be comparable to topical 5-FU. Pain and blistering and ulceration are common side effects.(16)

Photodynamic therapy with 5-aminolevulinic acid (ALA) or methyl aminolevulinate (MAL) has very good clearance rates of $93 \%$ even with single cycle, comparable to curettage, cryotherapy and 5-FU.(13,15,17) From currently available data, it has high level of evidence for its use in BD. It may be especially useful for larger lesions, difficult to treat or resistant sites such as the lower limbs.(15)

Topical 5-fluorouracil 5\% cream has shown clearance rates up to $92 \%$ in both short and longterm followup studies. Variable clearance rates are related to the different continuous and pulse therapy regimens of $5-\mathrm{FU}$. Topical imiquimod, an immunomodulator available as $5 \%$ cream, is an effective method of treatment of $\mathrm{BD}$ with cure rates ranging from $73 \%$ to $93 \%$. It is applied once daily for up to 16 weeks. It is generally well tolerated, may cause erythema and crusting.(15) The benefit of these topical agents is in difficult to treat areas and large lesions where surgical treatment is inconvenient. However, PDT is more efficacious in larger lesions.(15,16) This patient was started on topical 5-FU for the ease of topical therapy, since she was not willing for surgical methods of treatment. Newer modalities of treatment include topical diclofenac and lasers.(16)

\section{FINAL DIAGNOSIS}

Bowen's disease of the right arm.

\section{REFERENCES}

[1] Bowen JT. Centennial paper. May 1912 (J Cutan Dis Syph 1912;30:241-255). Precancerous dermatoses: a study of two cases of chronic atypical epithelial proliferation. By John T. Bowen, M.D., Boston. Arch Dermatol 1983;119(3):243-60.

[2] Cox NH, Eedy DJ, Morton CA. Guidelines for management of Bowen's disease. British association of dermatologists. Br J Dermatol 1999;141(4):633-41.

[3] Neagu TP, Ţigliş M, Botezatu D, et al. Clinical, histological and therapeutic features of Bowen's disease. Rom J Morphol Embryol 2017;58(1):33-40.

[4] Kossard S, Rosen R. Cutaneous Bowen's disease. An analysis of 1001 cases according to age, sex, and site. J Am Acad Dermatol 1992;27(3):406-10.

[5] Cox NH. Body site distribution of Bowen's disease. Br J Dermatol 1994;130(6):714-6.

[6] Ragi G, Turner MS, Klein LE, et al. Pigmented Bowen's disease and review of 420 Bowen's disease lesions. J Dermatol Surg Oncol 1988;14(7):765-9.

[7] Zawar VP, Tolat SN, Patil DJ, et al. Bowen's disease of multicentric origin. Indian J Dermatol Venereol Leprol 1993;59(5):266-8. 
[8] Mun JH, Kim SH, Jung DS, et al. Dermoscopic features of Bowen's disease in Asians. J Eur Acad Dermatol Venereol 2010;24(7):805-10.

[9] Emamzadehfard S, Ghaninejad H, Kamyab-Hesari K, et al. Dermoscopic-pathologic correlation of bowen disease: a case series and review of the literatures. J Clin Med Genomics 2016;4(1).

[10] Madke B, Doshi B, Khopkar U, et al. Appearances in dermatopathology: the diagnostic and the deceptive. Indian J Dermatol Venereol Leprol 2013;79(3):338-48.

[11] Cassarino DS, Derienzo DP, Barr RJ. Cutaneous squamous cell carcinoma: a comprehensive clinicopathologic classification. Part one. J Cutan Pathol 2006;33(3):191-206.

[12] Chuang TY, Tse J, Reizner GT. Bowen's disease (squamous cell carcinoma in situ) as a skin marker for internal malignancy: a case-control study. Am J Prev Med 1990;6(4):238-43.
[13] Bath-Hextall FJ, Matin RN, Wilkinson D, et al. Interventions for cutaneous Bowen's disease. Cochrane Database Syst Rev 2013;24(6):CD007281.

[14] Chisiki M, Kawada A, Akiyama M, et al. Bowen's disease showing spontaneous complete regression associated with apoptosis. $\mathrm{Br} J$ Dermatol 1999;140(5):939-44.

[15] Morley GL, Matthews JH, Verpetinske I, et al. A comparative study examining the management of Bowen's disease in the United Kingdom and Australia. Dermatol Res Pract Article ID 421460, 2015;2015:5.

[16] Morton CA, Birnie AJ, Eedy DJ. British Association of Dermatologists' guidelines for the management of squamous cell carcinoma in situ (Bowen's disease) 2014. Br J Dermatol 2014;170(2):245-60.

[17] Moreno G, Chia AL, Lim A, et al. Therapeutic options for Bowen's disease. Australas J Dermatol 2007;48(1):1-8; quiz 9-10. 